\title{
Executive functions in children and adolescents with hearing loss: A systematic review of case-control, case series, and cross-sectional studies
}

\author{
Jesús David Charry-Sánchez, ${ }^{1}$ Sofía Ramírez-Guerrero, ${ }^{2}$ María Paula Vargas-Cuellar, ${ }^{2}$ \\ María Alejandra Romero-Gordillo, ${ }^{2}$ Claudia Talero-Gutiérrez'
}

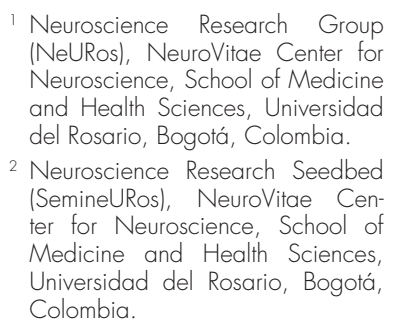

2 Neuroscience Research Seedbed (SemineURos), NeuroVitae Center for Neuroscience, School of Medicine and Health Sciences, Universidad del Rosario, Bogotá, Colombia

Correspondence:

Jesús David Charry-Sánchez

Neuroscience Research Group

(NeURos), NeuroVitae Center for

Neuroscience, School of Medicine

and Health Sciences, Universidad del Rosario.

Carrera 24 No. 63C-69

111221 Bogotá D.C., Colombia.

Phone: +573168727580

Email: jesus.charry@urosario.edu.co

Received: 17 February 2021

Accepted: 12 August 2021

Citation:

Charry-Sánchez, J. D., Ramírez-Guerrero, S. Vargas-Cuellar, M. P., Romero-Gordillo, M. A., \& Talero-Gutiérrez, C. (2022). Executive functions in children and adolescents with hearing loss: A systematic review of case-control, case series, and cross-sectional studies. Salud Mental, 45(1), 35-49

DOI: $10.17711 /$ SM.0185-3325.2022.006

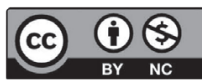

\begin{abstract}
Introduction. Children with hearing loss have been reported to perform lower in executive function and language tasks than their normal-hearing peers. Objective. To describe EF performance profile in children and adolescents with hearing loss. Method. Using different databases including PubMed, Scopus, and ScienceDirect, we conducted a systematic review of case-control, cross-sectional studies, and case series that evaluated executive function performance in children and adolescents with hearing loss with or without hearing aids, cochlear implants, and/or native sign language, since 2000 until April 2020. Fifteen studies were selected after quality assessment using Critical Appraisal Tools provided by Joanna Briggs Institute. Results. The studies differed in the assessment tools, and the results obtained by different authors were inconsistent. However, these studies revealed that children and adolescents with hearing impairment have lower performance in working memory, inhibition, cognitive flexibility, and attention than their normal-hearing peers. Discussion and conclusion. Executive function assessment tools are used indistinctively for both children with and without hearing loss. Consequently, as tools were designed for normal hearing population, results can significantly vary in the population with hearing impairment. Hence, it is important to establish a standardized protocol specifically adapted for this population.
\end{abstract}

Keywords: Children, cochlear implant, executive functions, hearing aids, hearing loss.

\section{RESUMEN}

Introducción. Se ha reportado que los niños con pérdida auditiva tienen un desempeño más bajo en pruebas de función ejecutiva y lenguaje en comparación con sus pares oyentes. Objetivo. Describir el perfil de desempeño en funciones ejecutivas en niños y adolescentes con pérdida auditiva. Método. Utilizando diferentes bases de datos incluidas PubMed, Scopus y ScienceDirect, se llevó a cabo una revisión sistemática de estudios de corte transversal, casos y controles y series de casos que evaluaron el desempeño en funciones ejecutivas de niños y adolescentes con pérdida auditiva con y sin audífonos, implante coclear y/o uso de lenguaje de señas desde 2000 hasta abril de 2020. Se seleccionaron 15 estudios usando el instrumento de evaluación de calidad del Instituto Joanna Briggs. Resultados. Los estudios utilizaron distintas herramientas de evaluación con resultados inconsistentes entre los diferentes autores. Sin embargo, los estudios reportaron que los niños y adolescentes con pérdida auditiva tienen un desempeño más bajo en memoria de trabajo, inhibición, flexibilidad cognitiva y atención que sus pares oyentes. Discusión y conclusión. Las herramientas de evaluación de función ejecutiva fueron empleadas indistintamente para niños con y sin pérdida auditiva. Teniendo en cuenta que las pruebas están diseñadas para la población oyente, los resultados pueden variar significativamente en la población con pérdida auditiva. De ahí la importancia de establecer un protocolo estandarizado adaptado para esta población.

Palabras clave: Niños, implante coclear, funciones ejecutivas, audífonos, pérdida auditiva. 


\section{INTRODUCTION}

Executive functions (EFs) are a set of skills that facilitate planning, organizing, and structuring daily life activities and long-term life goals (Blair, 2017; Doebel, 2020). EF are principally mediated by the frontal lobes, specifically by the prefrontal cortex, with its right dorsolateral area involved with monitoring behavior and its left dorsolateral area related to verbal processing. Both dorsolateral areas, together with the superior medial frontal lobe, are required for shifting, whereas the inferior medial frontal area contributes to response inhibition (Blair, 2017; Jurado \& Rosselli, 2007). EF performance is also associated with a series of neural circuits connecting the frontal lobes with subcortical structures (Goldstein, Naglieri, Princiotta, \& Otero, 2014; Royall et al., 2002).

Although EF are not directly associated with the symbolic processing of information, they are related to its control and organization, as well as the coordination and programming of movement and behaviors directed towards a purposeful activity (Corbett, Constantine, Hendren, Rocke, \& Ozonoff, 2009; Luria, 1977; Ustárroz, Molina, Lario, García, \& Lago, 2012). EF also include selective attention, working memory, and cognitive flexibility, which are required for concept formation and perceptual activity (Anderson, 2002; Gilbert \& Burgess, 2008; Ropovik, 2014). Furthermore, the structuring of logical syntax within coherent discourse and the modulation of behavior and affection in different scenarios are also considered to be EF-dependent abilities (Gilbert \& Burgess, 2008).

The domains of EF have been described by different authors; some have proposed that there are three categories, while others have suggested that there are more than five (Ardila \& Ostrosky-Solís, 2008; Diamond, 2013). However, most studies agree that EF include the following domains: inhibition, planning, working memory, cognitive flexibility, attention, problem solving, and reasoning, which are capacities that develop from early on in life (Flores-Lázaro, Castillo-Preciado, \& Jiménez-Miramonte, 2014).

Multiple tools have been used to measure the different EF skills including the Behavior Rating Inventory of Executive Function (BRIEF) 2 $2^{\text {nd }}$ edition, BRIEF-Preschool, National Institutes of Health (NIH) Toolbox Cognitive Assessment Battery, Stroop test, Tower of London test, Go/ No-Go task, Tower of Hanoi, Wisconsin Card Sorting Test, and subtests from the Wechsler Intelligence Scale for Children (WISC) (Chan, Shum, Toulopoulou, \& Chen, 2008; Delgado-Mejía \& Etchepareborda, 2013; Flores-Lázaro, Ostrosky-Solís, \& Lozano-Gutiérrez, 2008; Soprano, 2003). The BRIEF is a standardized questionnaire designed for parents, teachers, and caregivers to evaluate a child's real-life performance in eight domains of executive functions including inhibition, shifting, emotional control, working memory, plan/organize, organization of materials, and monitor. Contrastingly, other laboratory-based tools, such as the Stroop test and Tower of Hanoi, are carried out in a controlled environment to reduce biased results (Goldstein \& Naglieri, 2014).

On the other hand, the WISC IV and V, provides information about executive functions by examining specific tasks that require working memory and processing speed. WISC V evaluates five primary index scores including Verbal Comprehension Index (VCI), Visual Spatial Index (VSI), Working Memory Index (WMI), Fluid Reasoning Index (FRI), and Processing Speed Index (PSI), of which WMI, FRI, and PSI provide important information regarding performance in executive function. Additionally, it measures complementary index scales which indirectly measure working memory such as Naming Speed Index, Symbol Translation Index, and Storage and Retrieval Index. Compared to WISC IV, the fifth edition includes a revision of instructions for children's better comprehension of evaluating tasks and simplifies scoring criteria. Furthermore, both tests require trained evaluators with experience in child assessment and in the application of the test (Lace et al., 2020; Pearson Assessment, 2018).

Certain physical, emotional, and social factors are required for the adequate acquisition of EF (Diamond \& Lee, 2011). However, some conditions, such as hearing loss, may influence the optimal development of EF. Hearing loss is a treatable condition, which may interfere with normal neurodevelopment, especially in the acquisition of communication skills (Korver et al., 2017). Hearing loss can be classified according to the localization of damage (conductive, sensorineural, or mixed hearing loss), the degree of hearing loss (mild, moderate, severe, and profound), and its etiology (ASHA, 2016; Korver et al., 2017). Stevens et al. (2013) have reported that the prevalence of hearing loss in children between five to 14 years old can range from 1.0 to $2.2 \%$ and is more prevalent in boys than in girls. Furthermore, it has been found that as the population grows, the prevalence of hearing loss increases; in newborns, the prevalence is 1.33 per 1,000 live births, and 3.5 per 1,000 in adolescent population (Morton \& Nance, 2006; Watkin \& Baldwin, 2012).

Children with hearing loss may have language developmental delay of both comprehensive and expressive skills. Altered hearing afferences, either in the receptor or the transmission route, deprive the subject of adequate development of skills such as perception and auditory discrimination. The magnitude of the commitment will be related to the age of diagnosis and the beginning of rehabilitation, degree of hearing loss, and the use of hearing amplifiers or cochlear implant (Acosta Rodríguez, Ramírez Santana, \& Hernández Expósito, 2017). Language allows nomination, categorization, and generalization of the surrounding environment, favoring the development of abstraction capacity. As experience is enriched, and new information is provided, these abilities mature and constitute the basic pillars for 
cognition. Furthermore, language remains a key aspect in the capacity of self-monitor and self-regulation since the early developmental stages (Petersen, Bates, \& Staples, 2014). As a result, the delay in language development affects performance in both verbal and non-verbal assignments, which compromises performance in tasks related to executive functions (Perszyk \& Waxman, 2018).

Depending on the etiology and degree of hearing loss, the cognitive skills of these individuals vary. Nevertheless, the use of hearing aids or cochlear implants, combined with adequate language therapy will support the communication skills allowing them to perform tasks similar to those with normal hearing (Paluch et al., 2019; Yoshinaga-Itano, Sedey, Wiggin, \& Mason, 2018). However, speech is not the only way to communicate, for example, native sign language subjects have been found to perform at the same level as their hearing peers in the Auslan working memory span task (Wang \& Napier, 2013). Regarding the reading process, which involves functions such as attention, inhibition, and cognitive flexibility (Roldán, 2016), children with hearing loss, including cochlear implant users, have been found to perform lower in emergent literacy than their normal-hearing peers (Werfel, 2017). Furthermore, concept formation involves several abilities, including language, higher-order cognitive functions, and EF (Seel, 2012; Yoshida \& Smith, 2003). Castellanos et al. (2015) reported that, despite the use of a cochlear implant, children with hearing loss perform significantly lower in concept formation and abstraction tasks than their normal-hearing peers.

Table 1 $\mathrm{JBI}$ quality tools results for final selected articles

\begin{tabular}{lllrl}
\hline & \multicolumn{1}{c}{ Author } & \multicolumn{1}{c}{ Tool } & $\begin{array}{c}\text { Quality results } \\
(\%)\end{array}$ \\
\hline 1 & Al-Salim, S. et al. & Cohort & $9 / 11 \quad(82 \%)$ \\
2 & Beer, J. et al. & Cross sectional & $6 / 8 \quad(75 \%)$ \\
3 & Beer, J. et al. & Case and controls & $8 / 9 \quad(89 \%)$ \\
4 & Daza, M. T. et al. & Cohort & $6 / 8 \quad(75 \%)$ \\
5 & Ead, B. et al. & Case and control & $7 / 9 \quad(78 \%)$ \\
6 & Figueras, B. et al. & Case and control & $7 / 10 \quad(70 \%)$ \\
7 & Hall, et al. & Case and control & $10 / 10(100 \%)$ \\
8 & Holt, D. et al. & Cross sectional & $6 / 8 \quad(75 \%)$ \\
9 & Kirby, B. et al. & Cross sectional & $6 / 8 \quad(75 \%)$ \\
10 & Kronenberger, W. G. et al. & Cohort & $8 / 10 \quad(80 \%)$ \\
11 & Nittrouer, S. et al. & Case and control & $8 / 10 \quad(80 \%)$ \\
12 & Nunes, T. et al. & Case and control & $7 / 9 \quad(78 \%)$ \\
13 & Pagliaro \& Ansell & Cross sectional & $6 / 8 \quad(75 \%)$ \\
14 & Surowiecki, V. et al. & Case and control & $9 / 10 \quad(90 \%)$ \\
15 & Xuan, B. et al. & Case and control & $7 / 9 \quad(78 \%)$ \\
\hline
\end{tabular}

Note: Not all criteria were applicable to each article. The overall result (\%) excluded the criteria not applicable for each study.
Despite expanding research in EF, there are few studies that have explored EF performance in children with hearing loss. The aim of this systematic review of the literature was to describe the qualitative characteristics of EF performance in children and adolescents with hearing loss, with or without hearing aids, cochlear implants, and/or native sign language, and to propose methods that provide information about $\mathrm{EF}$ in this population taking into account their specific language characteristics.

\section{METHOD}

Protocol registration was submitted to PROSPERO; however, it was rejected due to the high demand of submissions regarding the COVID-19 pandemic. We conducted literature searches of different databases, including PubMed, Scopus, and ScienceDirect. The terms included in the search were as follows: "sensorineural hearing loss, deafness, hearing loss impairment, inhibition, attention, and executive functions." The search syntax used for PubMed was as follows: ((((sensorineural hearing loss) OR deafness) OR hearing loss impairment) AND inhibition) AND executive functions.

The first search carried out by three authors JCS, SRG, MVC, without any date restriction, revealed few unrelated articles published before the year 2000; therefore, the cut-off point was taken from that year on. The last search date was April 2020. The inclusion criteria were as follows: articles with cross-sectional, case-control, and case series design publications after 2000, subjects were under 18 years old, and no language filter was used. By limiting the age group to children and adolescents under 18 years old, it is possible to better discriminate congenital hearing loss

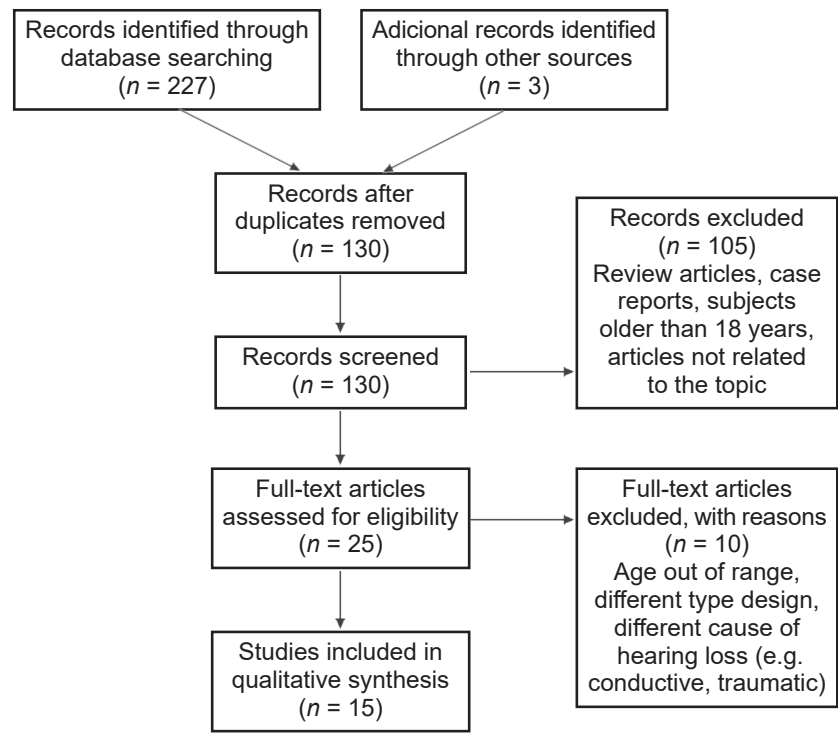

Figure 1. Prisma flow diagram. 
from other multifactorial etiologies that induce hearing loss in adult population. A total of 228 articles were identified. After manually removing duplicates by the first three authors, 128 references remained. Of these, 105 articles were filtered and eliminated by title and abstract, particularly those unrelated to the topic or that did not comply with the established inclusion criteria. All authors participated at this stage. In all author's periodic meetings, reasons for eliminating articles were clearly stated and discussed in detail. The following articles were excluded: review articles, case reports, publications with subjects older than 18 years, and papers unrelated to the topic. Data from the remaining 23 studies were analyzed using full-text and quality assessment that was supported by the Critical Appraisal Tools provided by Joanna Briggs Institute (Joanna Briggs Institute, 2017).
Each quality assessment tool is specifically designed for each type of study (cohort, case control, etc.), which were applied to each article accordingly. The quality result, as shown in Table 1, reports the relationship between the number of items achieved by the article over the total number of items evaluated. The final percentage must be $70 \%$ or more for the article to be considered in the review (Joanna Briggs Institute, 2017).

Of those 23 studies, 10 articles were further excluded because they were unrelated to the objectives of the search, the age of participants was outside the range, and the variables measured were not related to EF. Finally, 15 articles were selected for qualitative synthesis. Appendix was performed independently for each article as shown in Supplementary Data. Due to the lack of a standardized assessment tool for

Table 2

Cognitive domains compromised correlated with the degree of hearing loss

\begin{tabular}{|c|c|c|c|c|}
\hline Study & Year & $\begin{array}{l}\text { Number of subjects } \\
\text { with hearing loss }\end{array}$ & Degree of hearing loss & Cognitive domains compromised \\
\hline Ead et al. & 2013 & $7 / 14$ & Profound & $\begin{array}{l}\text { - Complex verbal working memory } \\
\text { - Verbal/Phonological processing }\end{array}$ \\
\hline Daza et al. & 2014 & $30 / 30$ & $\begin{array}{l}\text { Severe-to-profound, Mild-to-mod- } \\
\text { erate, cochlear implants and con- } \\
\text { ventional hearing aids }\end{array}$ & - No significant difference \\
\hline Al-Salim et al. & 2020 & $65 / 100$ & Mild, cochlear implant & $\begin{array}{l}\text { - Phonological processing } \\
\text { - Vocabulary } \\
\text { - Working memory } \\
\text { - Executive functions }\end{array}$ \\
\hline Kirby et al. & 2019 & $24 / 24$ & Mild, hearing aid & - No significant differences \\
\hline Beer et al. & 2014 & $24 / 45$ & Profound, cochlear implant & $\begin{array}{l}\text { - Executive functions } \\
\text { - Attention and inhibition }\end{array}$ \\
\hline Surowiecki et al. & 2002 & $48 / 48$ & $\begin{array}{l}\text { Profound, Severe, Moder- } \\
\text { ate-to-severe, cochlear implants }\end{array}$ & - No significant differences \\
\hline Xuan et al. & 2018 & $36 / 72$ & Profound & - Decision-making \\
\hline Nittrouer et al. & 2012 & $35 / 52$ & $\begin{array}{l}\text { Severe-to-profound, Moderate, } \\
\text { cochlear implants }\end{array}$ & $\begin{array}{l}\text { - Emergent literacy } \\
\text { - Oral language skills }\end{array}$ \\
\hline Figueras et al. & 2008 & $47 / 69$ & $\begin{array}{l}\text { Profound, Moderate, Severe, co- } \\
\text { chlear implants }\end{array}$ & - Intelligence \\
\hline Holt et al. & 2013 & $59 / 59$ & Cochlear implants & $\begin{array}{l}\text { - Inhibitory control } \\
\text { - Language and vocabulary development } \\
\text { - Shifting attention } \\
\text { - Working memory }\end{array}$ \\
\hline Nunes et al. & 2009 & $55 / 133$ & $\begin{array}{l}\text { Moderate, Severe-to-profound, } \\
\text { cochlear implants }\end{array}$ & - Multiplicative reasoning \\
\hline Pagliaro \& Ansell & 2012 & $59 / 59$ & $\begin{array}{l}\text { Mild, moderate, severe, pro- } \\
\text { found, cochlear implants }\end{array}$ & - Problem-solving \\
\hline Hall et al. & 2018 & $71 / 116$ & Cochlear implant, sign language & $\begin{array}{l}\text { - Inhibition } \\
\text { - Working memory }\end{array}$ \\
\hline Beer et al. & 2011 & $45 / 45$ & Cochlear implant & $\begin{array}{l}\text { - Inhibition } \\
\text { - Working memory }\end{array}$ \\
\hline Kronenberger et al. & 2020 & $41 / 81$ & Cochlear implant & $\begin{array}{l}\text { - Language } \\
\text { - Inhibition } \\
\text { - Working memory }\end{array}$ \\
\hline
\end{tabular}


children and adolescents with hearing loss, there was insufficient data for quantitative analysis, therefore, a qualitative analysis was preferred. This systematic review was conducted using the parameters established by the PRISMA Statement (Figure 1; Moher, Liberati, Tetzlaff, \& Altman, 2009).

\section{RESULTS}

Among the 15 studies analyzed, there were seven case-control and six cross-sectional studies. The age range was from one to 18 years, with more frequent cases including those between the age ranges of six to 18 years. Some studies did not report the sex of the cases; those that reported sex found no significant difference between male and female participants. However, there was great variability in the number of subjects from seven to 71. Table 2 describes the main variables of each study.

Although all articles included objective measures for executive function, it was not possible to synthetize and compare them using the same criteria due to the variety of assessment tools used. Each study evaluated different skills: some used specific tests for children with hearing loss, while others applied tests designed for the general population. The assessment tools are outlined in Table 3.

As a standardized measure to classify hearing loss, most studies recorded the degrees of hearing loss based on pure-tone average (PTA). Only some studies used the classification established by the American Speech-LanguageHearing Association (ASHA, 2016; Clark, 1981; Table 4).

Some studies failed to report the methodology used to group subjects, so it remained unclear whether such grouping was based on hearing level or threshold ranges to establish the degree of hearing loss. Moreover, the studies that included children with cochlear implants reported variable durations of device use (from .5 to 16 years), as well as varying ages of implantation (from approximately one year to 3.5 years).

In terms of children with normal hearing, some studies recruited age- and sex-matched controls (Surowiecki et al., 2002), while others included subjects' siblings to control sociodemographic factors that may have an effect on children's overall performance (Ead, Hale, DeAlwis, \& Lieu, 2013). The allocation of children with both sensorineural and conductive hearing loss to the same group in one study (Al-Salim, Moeller, \& McGregor, 2020) contrasts with the rest of the studies, which only focused on sensorineural hearing loss.

There was no uniformity in the results obtained by different authors. While some reported success in different sets of skills, others reported a significantly lower performance on the same tasks (Figueras, Edwards, \& Langdon, 2008).

Some studies found no significant difference in performance in EFs between children with normal hearing and those with hearing loss, independent of the degree of hearing loss and the type of hearing aid or cochlear implant (Beer et al., 2014; Daza, Phillips-Silver, Ruiz-Cuadra, \& López-López, 2014; Figueras et al., 2008; Hall, Eigsti, Bortfeld, \& Lillo-Martin, 2018; Kirby, Spratford, Klein, \& McCreery, 2019; Nittrouer, Caldwell, Lowenstein, Tarr, \& Holloman, 2012; Surowiecki et al., 2002). According to this finding, the following EFs of children with hearing loss was not different to those with normal hearing: inhibition, working memory, attention, visual attention, visual memory, cognitive flexibility, and planning/organizing (Beer, Kronenberger, \& Pisoni, 2011; Beer et al., 2014; Figueras et al., 2008; Hall et al., 2018; Kirby et al., 2019; Kronenberger, Xu, \& Pisoni, 2020; Surowiecki et al., 2002). Furthermore, children with hearing loss had similar comprehensive and expressive vocabulary and phonological skills as those with normal hearing (Daza et al., 2014; Nittrouer et al., 2012). Nonetheless, another study reported that children fluent in verbal or sign communication performed better than those who did not, independent of their hearing loss (Hall et al., 2018). Similarly, children with good family support, including maternal sensitivity, use of oral language, organization and control at home, supportiveness and cohesion among family members, family size, and education level, tended to have better emotional and inhibitory control (Holt, Beer, Kronenberger, \& Pisoni, 2013). Conversely, several studies reported that children with hearing loss performed significantly lower than those with normal hearing in EFs, such as working memory, inhibition, cognitive flexibility, and attention (Beer et al., 2014; Figueras et al., 2008; Hall et al., 2018; Kirby et al., 2019; Kronenberger et al., 2020; Surowiecki et al., 2002).

\section{DISCUSSION AND CONCLUSION}

\section{The role of language in overall performance of children and adolescents with hearing loss}

The results of this systematic review indicate that children with deafness have a lower performance in hearing skills, from phonological discrimination to verbal reasoning, which are acquired later, regardless of whether the child had a cochlear implant or some other hearing aid. If stimuli are presented in a multiple-choice format or if recognition is limited to hearing, deaf children presented greater difficulties; however, if these were accompanied by visual clues, performance was improved (Al-Salim et al., 2020). Despite the use of cochlear implants or hearing aids, children with hearing loss do not have the same linguistic development as their hearing peers (Ambrose, Fey, \& Eisenberg, 2012; Colin, Leybaert, Ecalle, \& Magnan, 2013; Nittrouer et al., 2012). For example, James, Rajput, Brinton, and Goswami, (2008) found that children who had received cochlear 
Table 3

Executive functions assessment tools used in the 15 studies

\begin{tabular}{|c|c|}
\hline \multicolumn{2}{|l|}{ Assessment tools } \\
\hline Attention & Inhibition \\
\hline $\begin{array}{l}\text { - Child Neuropsychological Maturity Questionnaire computer- } \\
\text { ized version }\end{array}$ & - Go/No-Go task \\
\hline - The Intradimensional/Extradimensional Set Shift Task & - Flanker Inhibitory Control task \\
\hline \multicolumn{2}{|l|}{ - The Tower of London test } \\
\hline \multicolumn{2}{|l|}{ - Attention subtest of the NIH toolbox } \\
\hline \multicolumn{2}{|l|}{$\begin{array}{l}\text { - Attention Sustained subtest of the Leiter International Per- } \\
\text { formance Scale }\end{array}$} \\
\hline Intelligence & Executive functions \\
\hline - Wechsler Abbreviated Scale of Intelligence & - Short-term memory task \\
\hline - Wechsler Intelligence Scale for Children IV & $\begin{array}{l}\text { - From NEPSY battery: Tower, Visual Attention, Design Fluency, and } \\
\text { Knock and Tap }\end{array}$ \\
\hline - The Picture Similarities subtest of the Differential Ability Scales & - Day-Night and One-Two tasks \\
\hline - Raven's Progressive Matrices & - From de D-KEFS battery: Card Sorting test \\
\hline \multirow[t]{6}{*}{ - The Hiskey-Nebraska Test of Learning Aptitude } & - Behavior Rating Inventory of Executive Function \\
\hline & - Behavior Rating Inventory of Executive Function-Preschool \\
\hline & - Dimensional Change Card Sort \\
\hline & - NIH Toolbox Cognitive Assessment Battery \\
\hline & - Beery Developmental Test of Visual Motor Integration \\
\hline & - Decision-Making tasks: lowa Gambling Task and Game of Dice Task \\
\hline Memory & Language, vocabulary, speech, and phonological abilities \\
\hline Working memory & Language \\
\hline - Letter Span Tasks & - The Preschool Language Scale 4th edition \\
\hline - Counting Span Tasks & - Clinical Evaluation of Language Fundamentals preschool test \\
\hline $\begin{array}{l}\text { - Counting Recall subtest of the Automated Working Memory } \\
\text { Assessment }\end{array}$ & $\begin{array}{l}\text { - The Auditory Comprehension subtest of the Preschool Language } \\
\text { Scales 4th edition }\end{array}$ \\
\hline - Nonword repetition task & - Nonword repetition task \\
\hline - The Spatial Working Memory task & - Spectral-temporally Modulated Ripple test \\
\hline Visuospatial/spatial memory & - Aided Speech Intelligibility Index \\
\hline - Visuospatial Memory Span Tasks & - The Expressive One-Word Picture Vocabulary test \\
\hline - Kaufman Assessment Battery for Children & - The British Picture Vocabulary Scale \\
\hline - Memory for Designs subtest of the NEPSY-II & - The Test for Reception of Grammar \\
\hline - The Pattern and Spatial Recognition test & - Bamford-Kowal-Bench Sentence List \\
\hline - The Delayed Matching to Sample test & - Consonant-Nucleus-Consonant word lists \\
\hline - The Paired Associates test & Vocabulary \\
\hline - Corsi block task & - Peabody Picture Vocabulary Test Revised \\
\hline Short-term visual memory & - Carolina Picture Vocabulary Test for Deaf and Hearing Impaired Children \\
\hline \multirow[t]{9}{*}{ - Memory of Faces task } & - Vocabulary subtest of the Wechsler Abbreviated Scale of Intelligence II \\
\hline & Speech \\
\hline & $\begin{array}{l}\text { - The Northwestern University Children's Perception of Speech closed } \\
\text { consonant perception test }\end{array}$ \\
\hline & Phonological abilities \\
\hline & - Comprehensive Test of Phonological Processing \\
\hline & - Rhyme Judgment Requiring Picture Selection \\
\hline & - Psycholinguistic Assessments of Language Processing in Aphasia \\
\hline & - Initial Consonant Same-Different task \\
\hline & - The Final Consonant Choice task \\
\hline
\end{tabular}


Table 4

ASHA - Degrees of hearing loss

\begin{tabular}{lc}
\hline Degree of hearing loss & Hearing loss range $(\mathrm{dB} \mathrm{HL})$ \\
\hline Normal & -10 to 15 \\
Slight & 16 to 25 \\
Mild & 26 to 40 \\
Moderate & 41 to 55 \\
Moderately severe & 56 to 70 \\
Severe & 71 to 90 \\
Profound & $91+$ \\
\hline
\end{tabular}

Note: (ASHA, 2016).

implantation at an early age had a lower performance in phonological awareness compared with the normal-hearing controls. However, Svirsky, Robbins, Kirk, Pisoni, and Miyamoto (2000) reported that cochlear implantation at an early age can improve language development when compared with children with conventional hearing aids. Furthermore, Figueras et al. (2008) reported that children with cochlear implants have a better response to auditory stimuli as well as improved speech and language skills compared with children with other hearing aids. Such differences in language development may contribute to the variability of the results of the studies included, not only between children with hearing loss and children with normal hearing, but also among children with different types of hearing aids.

The performance of deaf children in vocabulary tasks varied between the studies included. Grammar difficulties in children with hearing loss were also reported (AlSalim et al., 2020; Daza et al., 2014; Figueras et al., 2008; Nittrouer et al., 2012). Variations in grammar skills in children with hearing loss can be attributed to greater delays in their syntax acquisition and difficulties in hearing essential morphemes compared with children with normal hearing, which represent an additional barrier in the learning of new words (Moeller \& Tomblin, 2015). Such struggles with the acoustic-phonetic properties of spoken language mean that children with hearing loss have a limited access to linguistic input and, as a consequence, a reduction in language experience (Moeller \& Tomblin, 2015).

Reading skills and mathematical problem solving are associated with language development, and children with hearing loss had less efficient reading and mathematical problem-solving skills; however, children with hearing loss were able to increase their reading ability via alternative routes, such as visual attention and visual memory (Daza et al., 2014; Nunes et al., 2009). Children with normal hearing, as well as those with hearing loss, have been shown to use similar strategies for mathematical problem solving (Pagliaro \& Ansell, 2012).

\section{Types of hearing loss, hearing aids and communication skills}

Although some studies employed the same parameters to evaluate hearing loss, such as PTA, there was a great variability between the studies in the degree of hearing loss; indeed, some authors selected their own thresholds and did not consider the parameters established by the ASHA (2016) or the World Health Organization (2020). Hearing aids and cochlear implants also vary in their time of use, and there is no clear information regarding their functional aspects, which challenges the validity of this comparison. Nittrouer et al. (2012) identified moderately strong correlations between the age of implantation and both phonemic awareness and auditory comprehension. In addition, Niparko et al. (2010) found better language comprehension and expression in children with earlier cochlear implants. Therefore, the longer use of cochlear implants improves phonological awareness (Nittrouer et al., 2012). Additionally, Nicholas and Geers (2007) found higher performance levels in children who received a more advanced implant technology. This means that technological differences in cochlear implants used could contribute to variations in performance.

While some studies were limited to children with unilateral hearing loss only (Ead et al., 2013), others compared children with unilateral hearing loss, bilateral hearing loss, and those with cochlear implants within the same study (AlSalim et al., 2020). Considering that children with unilateral hearing loss may have a normal hearing level in the unaffected ear, their performance is not comparable with that of children with bilateral hearing loss (Lieu, 2004). Differences between children with unilateral hearing loss and children with bilateral hearing loss or normal hearing are largely due to the change from binaural to monoaural sound inputs to the brain. This has been shown to affect the development of cognitive functions and the ability to localize sound (Lewis, Smith, Spalding, \& Valente, 2018; Lieu, 2004; Schmithorst, Plante, \& Holland, 2014).

It is noteworthy to mention that, in one study, children who used Spanish sign language were compared with spoken Spanish rehabilitated subjects, and their performance was similar to those reported by other authors (Daza et al., 2014). Other work included children that used native American sign language and showed no significant difference in EFs compared to children with cochlear implants, children with hearing loss, and normal hearing peers (Hall et al., 2018).

Children with hearing loss have developmental differences regarding communication skills and cognitive abilities depending on the etiology, degree of hearing loss, family support, early diagnosis, and type and time of rehabilitation, which make it difficult to compare them under the same criteria. However, defining a global developmen- 
tal trend in executive function in this population outlines their strengths and weaknesses which can be used to better direct their rehabilitation (Korver et al., 2017; Niparko et al., 2010; The Joint Committee of Infant Hearing, 2019).

\section{Executive function performance in hearing loss}

The performance of children with hearing impairment on the tasks related to EF, such as working memory, inhibition, cognitive flexibility, and attention, tended to be inconsistent among the studies reviewed. Such inconsistencies could be attributed to the use of different methods of evaluation. (Hall, Eigsti, Bortfeld, \& Lillo-Martin, 2017), which highlights the need for a standardized tool for this population.

Out of the fifteen articles analyzed, only three reported no significant differences between the population groups studied. One of them studied children with cochlear implants compared to children with hearing aids; therefore, there was no normal hearing control group to compare them with (Surowiecki et al., 2002). Another one focused on specific aspects such as comparing good and bad readers regarding phonological skills (Daza et al., 2014), while the other used tests like the Spectral-temporally modulated ripple test which is specific for the population with cochlear implants with no comparable results to normal hearing population (Kirby et al., 2019).

Kronenberger, Pisoni, Henning, and Colson (2013) mentioned that despite the prolonged use of cochlear implants, the performance in EFs, particularly working memory, verbal fluency, inhibition, and attention, was lower in deaf individuals compared to their normal hearing peers.

These findings are consistent with the period of deafness that occurs prior to the diagnosis and intervention which represent a critical moment in neurodevelopment. This means that children with hearing loss are deprived of important auditory information that influences language development (Kronenberger et al., 2013).

The studies that used the BRIEF and BRIEF-P showed that parents reported a lower performance in tasks related to attention, inhibitory control, and working memory; some authors also included shifting attention in this list (Beer et al., 2014; Hall et al., 2018; Kronenberger et al., 2020). These findings have been supported by other reports that children with cochlear implants presented with difficulties in working memory and inhibitory control scales, as well as in the behavioral regulation index, according to parent reports (Beer et al., 2011). Kronenberger et al. (2013) established that verbal skills are directly involved with EFs; therefore, children with hearing loss who present a delay in language acquisition are expected to have suboptimal development in processes used for directing and controlling thoughts and behavior, thereby explaining the parent-reported deficit in areas such as inhibitory control. It is worth noting that the articles included in this review only report the parents' perception of children's performance. Other studies have included both parent and teacher reports and have highlighted the differences between them regarding specific EFs. Sabat, Arango, Tassé, and Tenorio (2020) attribute this disagreement to the different skills that children are expected to acquire in the corresponding environment. As a result, children who are exposed to a constant learning of new concepts, as occurs in a classroom environment, require EF such as inhibition and cognitive flexibility to adapt effectively. In contrast, at home children are expected to develop more predictable adaptive skills involving other EF domains such as working memory (Sabat et al., 2020). Therefore, EF deficits can be perceived as more or less severe depending on the demand in the different settings.

\section{Contributions and future implications}

Given the range of causes and degree of hearing loss, time of diagnosis, and beginning of rehabilitation therapy, performance in EF is expected to vary. Furthermore, hearing loss in developed countries is mainly attributed to genetic causes, whereas in developing countries are more common hearing loss secondary to infectious and other preventable causes (Korver et al., 2017).

As seen in Table 3, a wide range of assessment tools were used. This indicates that there are no uniform criteria for the evaluation of EF in children with hearing loss. Despite the variability of assessment tools employed in the evaluation of this population, the selected studies indicated that children with hearing impairment had a lower performance in working memory, inhibition, cognitive flexibility, and attention measures (Botting et al., 2017). These findings highlight the importance of developing or adapting an objective, reliable, and standardized evaluating tool to assess EF according to this population's specific characteristics.

Despite the variability of tests and types of studies evaluated, there are evident weaknesses in EF performance in this population. This represents a therapeutic and rehabilitation target for them to access better long term educational and professional opportunities. Furthermore, a multidisciplinary team is required to improve the understanding of parents about their children's condition, such as the John Tracy Center. They provide structured support programs according to age-group, family structure, and specific individual characteristics (JTC, 2021).

\section{Funding}

None.

\section{Conflict of interest}

The authors declare they have no conflicts of interest.

\section{Acknowledgments}

We thank Nia Cason, $\mathrm{PhD}$, from Edanz Group (https://en-author-services.edanzgroup.com/ac) for editing a draft of this manuscript. 


\section{REFERENCES}

Acosta Rodríguez, V., Ramírez Santana, G. M., \& Hernández Expósito, S. (2017). Executive functions and language in children with different subtypes of specific language impairment. Neurología (English Edition), 32(6), 355-362. doi: 10.1016/j.nrleng.2015.12.007

Al-Salim, S., Moeller, M. P., \& McGregor, K. K. (2020). Performance of children with hearing loss on an audiovisual version of a nonword repetition task. Language, Speech, and Hearing Services in Schools, 51(1), 42-54. doi: 10.1044/2019_ LSHSS-OCHL-19-0016

Ambrose, S. E., Fey, M. E., \& Eisenberg, L. S. (2012). Phonological awareness and print knowledge of preschool children with cochlear implants. Journal of Speech, Language, and Hearing Research, 55(3), 811-823. doi: 10.1044/10924388(2011/11-0086)

American Speech Language Hearing Association, ASHA. (2016). Tipo, grado y configuración de la pérdida de audición. Retrieved from https://www.asha.org/ uploadedFiles/Tipo-grado-y-configuracion-de-la-perdida-de-audicion.pdf

Anderson, P. (2002). Assessment and development of executive function (EF) during childhood. Child Neuropsychology, 8(2), 71-82. doi: 10.1076/chin.8.2.71.8724

Ardila, A., \& Ostrosky-Solís, F. (2008). Desarrollo histórico de las funciones ejecutivas. Revista Neuropsicología, Neuropsiquiatría y Neurociencias, 8(1), 1-21.

Beer, J., Kronenberger, W. G., \& Pisoni, D. B. (2011). Executive function in everyday life: Implications for young cochlear implant users. Cochlear Implants International, 12(Suppl 1), S89-S91. doi: 10.1179/146701011X130010357525 70

Beer, J., Kronenberger, W. G., Castellanos, I., Colson, B. G., Henning, S. C., \& Pisoni, D. B. (2014). Executive functioning skills in preschool-age children with cochlear implants. Journal of Speech, Language, and Hearing Research: JSLHR, 57(4), 1521-1534. doi: 10.1044/2014_JSLHR-H-13-0054

Blair, C. (2017). Educating executive function. Wiley Interdiscip Rev Cogn Sci, 8(12), e1403. doi: 10.1002/wcs.1403

Botting, N., Jones, A., Marshall, C., Denmark, T., Atkinson, J., \& Morgan, G. (2017). Nonverbal executive function is mediated by language: A study of deaf and hearing children. Child Development, 88(5), 1689-1700. doi: 10.1111/ cdev. 12659

Castellanos, I., Kronenberger, W. G., Beer, J., Colson, B. G., Henning, S. C., Ditmars, A., \& Pisoni, D. B. (2015). Concept formation skills in long-term cochlear implant users. Journal of Deaf Studies and Deaf Education, 20(1), 27-40. doi: 10.1093/deafed/enu039

Chan, R. C. K., Shum, D., Toulopoulou, T., \& Chen, E. Y. H. (2008). Assessment of executive functions: Review of instruments and identification of critical issues. Archives of Clinical Neuropsychology, 23(2), 201-216. doi: 10.1016/j. acn.2007.08.010

Clark, J. G. (1981). Uses and abuses of hearing loss classification. ASHA, 23(7), 493500.

Colin, S., Leybaert, J., Ecalle, J., \& Magnan, A. (2013). The development of word recognition, sentence comprehension, word spelling, and vocabulary in children with deafness: A longitudinal study. Research in Developmental Disabilities, 34(5), 1781-1793. doi: 10.1016/j.ridd.2013.02.001

Corbett, B. A., Constantine, L. J., Hendren, R., Rocke, D., \& Ozonoff, S. (2009). Examining executive functioning in children with autism spectrum disorder, attention deficit hyperactivity disorder and typical development. Psychiatry Research, 166(2-3), 210-222. doi: 10.1016/j.psychres.2008.02.005

Daza, M. T., Phillips-Silver, J., Ruiz-Cuadra, M. del M., \& López-López, F. (2014). Language skills and nonverbal cognitive processes associated with reading comprehension in deaf children. Research in Developmental Disabilities, 35(12), 3526-3533. doi: 10.1016/j.ridd.2014.08.030

Delgado-Mejía, I. D., \& Etchepareborda, M. C. (2013). Trastornos de las funciones ejecutivas. Diagnóstico y tratamiento. Revista de Neurología, 57(Supp1 1), S95-S103

Diamond, A. (2013). Executive functions. Annual Review of Psychology, 64, 135168. doi: 10.1146/annurev-psych-113011-143750

Diamond, A., \& Lee, K. (2011). Interventions shown to aid executive function development in children 4 to 12 years old. Science, 333(6045), 959-964. doi: $10.1126 /$ science. 1204529
Doebel, S. (2020). Rethinking Executive Function and Its Development. Perspectives on Psychological Science, 15(4), 942-956. doi: 10.1177/1745691620904771

Ead, B., Hale, S., DeAlwis, D., \& Lieu, J. (2013). Pilot study of cognition in children with unilateral hearing loss. International Journal of Pediatric Otorhinolaryngology, 77(11), 1856-1860. doi: 10.1016/j.ijporl.2013.08.028

Figueras, B., Edwards, L., \& Langdon, D. (2008). Executive function and language in deaf children. Journal of Deaf Studies and Deaf Education, 13(3), 362-377. doi: 10.1093/deafed/enm067

Flores-Lázaro, J. C., Castillo-Preciado, R. E., \& Jiménez-Miramonte, N. A. (2014). Desarrollo de funciones ejecutivas, de la niñez a la juventud. Anales de Psicología, 30(2), 463-473. doi: 10.6018/analesps.30.2.155471

Flores-Lázaro, J. C., Ostrosky-Solís, F., \& Lozano-Gutiérrez, A. (2008). Batería de Funciones Frontales y Ejecutivas: Presentación. Revista Neuropsicología, Neuropsiquiatría y Neurociencias, 8(1), 141-158.

Gilbert, S. J., \& Burgess, P. W. (2008). Executive function. Current Biology, 18(3), R110-R114. doi: 10.1016/j.cub.2007.12.014

Goldstein, S., \& Naglieri, J. A. (2014). Handbook of Executive Functioning (pp. 1-567). Springer Science + Business Media. doi: 10.1007/978-1-4614-8106-5

Goldstein, S., Naglieri, J. A., Princiotta, D., \& Otero, T. M. (2014). Introduction: A history of executive functioning as a theoretical and clinical construct. In S. Goldstein \& J. A. Naglieri (Eds.), Handbook of executive functioning (pp. 3-12). doi: 10.1007/978-1-4614-8106-5_1

Hall, M. L., Eigsti, I.-M., Bortfeld, H., \& Lillo-Martin, D. (2017). Auditory deprivation does not impair executive function, but language deprivation might: Evidence from a parent-report measure in deaf native signing children. Journal of Deaf Studies and Deaf Education, 22(1), 9-21. doi: 10.1093/deafed/ enw054

Hall, M. L., Eigsti, I.-M., Bortfeld, H., \& Lillo-Martin, D. (2018). Executive function in deaf children: Auditory access and language access. Journal of Speech, Language, and Hearing Research, 61(8), 1970-1988. doi: 10.1044/2018_ JSLHR-L-17-0281

Holt, R. F., Beer, J., Kronenberger, W. G., \& Pisoni, D. B. (2013). Developmental effects of family environment on outcomes in pediatric cochlear implant recipients. Otology \& Neurotology, 34(3), 388-395. doi: 10.1097/ MAO.0b013e318277a0af

James, D., Rajput, K., Brinton, J., \& Goswami, U. (2008). Phonological awareness, vocabulary, and word reading in children who use cochlear implants: Does age of implantation explain individual variability in performance outcomes and growth? Journal of Deaf Studies and Deaf Education, 13(1), 117-137. doi: 10.1093/deafed/enm042

Joanna Briggs Institute. (2017). Critical Appraisal Tools. Retrieved from https://jbi. global/critical-appraisal-tools

JTC. (2021). John Tracy Center. Retrieved from https://www.jtc.org/

Jurado, M. B., \& Rosselli, M. (2007). The elusive nature of executive functions: A review of our current understanding. Neuropsychology Review, 17(3), 213-233. doi: $10.1007 / \mathrm{s} 11065-007-9040-\mathrm{z}$

Kirby, B. J., Spratford, M., Klein, K. E., \& McCreery, R. W. (2019). Cognitive abilities contribute to spectro-temporal discrimination in children who are hard of hearing. Ear and Hearing, 40(3), 645-650. doi: 10.1097/ AUD.0000000000000645

Korver, A. M. H., Smith, R. J. H., Van Camp, G., Schleiss, M. R., Bitner-Glindzicz, M. A. K., Lustig, L. R., ... Boudewyns, A. N. (2017). Congenital hearing loss. Nature Reviews. Disease Primers, 3, 16094. doi: 10.1038/nrdp.2016.94

Kronenberger, W. G., Pisoni, D. B., Henning, S. C., \& Colson, B. G. (2013). Executive functioning skills in long-term users of cochlear implants: A case control study. Journal of Pediatric Psychology, 38(8), 902-914. doi: 10.1093/jpepsy/jst034

Kronenberger, W. G., Xu, H., \& Pisoni, D. B. (2020). Longitudinal development of executive functioning and spoken language skills in preschool-aged children with cochlear implants. Journal of Speech, Language, and Hearing Research, 63(4), 1128-1147. doi: 10.1044/2019_JSLHR-19-00247

Lace, J. W., Merz, Z. C., Kennedy, E. E., Seitz, D. J., Austin, T. A., Ferguson, B. J., \& Mohrland, M. D. (2020). Examination of five- and four-subtest short form IQ estimations for the Wechsler Intelligence Scale for Children-Fifth edition (WISC-V) in a mixed clinical sample. Applied Neuropsychology: Child, 1-12. doi: $10.1080 / 21622965.2020 .1747021$ 
Lewis, D. E., Smith, N. A., Spalding, J. L., \& Valente, D. L. (2018). Looking behavior and audiovisual speech understanding in children with normal hearing and children with mild bilateral or unilateral hearing loss. Ear and Hearing, 39(4), 783-794. doi: 10.1097/AUD.0000000000000534

Lieu, J. E. C. (2004). Speech-language and educational consequences of unilateral hearing loss in children. Archives of Otolaryngology--Head \& Neck Surgery, 130(5), 524-530. doi: 10.1001/archotol.130.5.524

Luria, A. R. (1977). Las funciones corticales superiores del hombre. Editorial Orbe.

Moeller, M. P., \& Tomblin, J. B. (2015). An introduction to the outcomes of children with hearing loss study. Ear and Hearing, 36(Suppl 1), 4S-13S. doi: 10.1097/ AUD.0000000000000210

Moher, D., Liberati, A., Tetzlaff, J., \& Altman, D. G. (2009). Preferred reporting items for systematic reviews and meta-analyses: The PRISMA Statement. PLoS Medicine, 6(7), e1000097. doi: 10.1371/journal.pmed.1000097

Morton, C. C., \& Nance, W. E. (2006). Newborn hearing screening-A silent revolution. New England Journal of Medicine, 354(20), 2151-2164. doi: 10.1056/NEJMra050700

Nicholas, J. G., \& Geers, A. E. (2007). Will they catch up? The role of age at cochlear implantation in the spoken language development of children with severeprofound hearing loss. Journal of Speech, Language, and Hearing Research, 50(4), 1048-1062. doi: 10.1044/1092-4388(2007/073)

Niparko, J. K., Tobey, E. A., Thal, D. J., Eisenberg, L. S., Wang, N.-Y., Quittner, A. L., ... CDaCI Investigative Team. (2010). Spoken language development in children following cochlear implantation. JAMA, 303(15), 1498-1506. doi: 10.1001/jama.2010.451

Nittrouer, S., Caldwell, A., Lowenstein, J. H., Tarr, E., \& Holloman, C. (2012). Emergent literacy in kindergartners with cochlear implants. Ear and Hearing, 33(6), 683-697. doi: 10.1097/AUD.0b013e318258c98e

Nunes, T., Bryant, P., Burman, D., Bell, D., Evans, D., \& Hallett, D. (2009). Deaf children's informal knowledge of multiplicative reasoning. Journal of Deaf Studies and Deaf Education, 14(2), 260-277. doi: 10.1093/deafed/enn040

Pagliaro, C. M., \& Ansell, E. (2012). Deaf and hard of hearing students' problemsolving strategies with signed arithmetic story problems. American Annals of the Deaf, 156(5), 438-458. doi: 10.1353/aad.2012.1600

Paluch, P., Kochański, B., Ganc, M., Cieśla, K., Milner, R., Pluta, A., \& Lewandowska, M. (2019). Early general development and central auditory system maturation in children with cochlear implants - A case series. International Journal of Pediatric Otorhinolaryngology, 126, 109625. doi: 10.1016/j.ijporl.2019.109625

Pearson Assessment. (2018). WISC--V Efficacy Research Report - April (pp. 1-42).

Perszyk, D. R., \& Waxman, S. R. (2018). Linking Language and Cognition in Infancy. Annual Review of Psychology, 69, 231-250. doi: 10.1146/annurevpsych-122216-011701

Petersen, I. T., Bates, J. E., \& Staples, A. D. (2014). The role of language ability and self-regulation in the development of inattentive-hyperactive behavior problems. Development and Psychopathology, 27(1), 221-237. doi: 10.1017/ S0954579414000698

Roldán, L. A. (2016). Inhibition and updating in text comprehension: A review. Universitas Psychologica, 15(2), 87-95. doi: 10.11144/Javeriana.upsy15-2.iact

Ropovik, I. (2014). Do executive functions predict the ability to learn problemsolving principles? Intelligence, 44, 64-74. doi: 10.1016/j.intell.2014.03.002

Royall, D. R., Lauterbach, E. C., Cummings, J. L., Reeve, A., Rummans, T. A., Kaufer, D. I., ... Coffey, C. E. (2002). Executive control function: A review of its promise and challenges for clinical research. A report from the Committee on Research of the American Neuropsychiatric Association. Journal of Neuropsychiatry and Clinical Neurosciences, 14(4), 377-405. doi: 10.1176/ jnp.14.4.377

Sabat, C., Arango, P., Tassé, M. J., \& Tenorio, M. (2020). Different abilities needed at home and school: The relation between executive function and adaptive behaviour in adolescents with Down syndrome. Scientific Reports, 10(1), 1683. doi: 10.1038/s41598-020-58409-5

Schmithorst, V., Plante, E., \& Holland, S. K. (2014). Unilateral deafness in children affects development of multi-modal modulation and default mode networks. Frontiers in Human Neuroscience, 8, 164. doi: 10.3389/fnhum.2014.00164

Seel, N. M. (2012). Concept formation: Characteristics and functions. In N. M. Seel (Ed.), Encyclopedia of the Sciences of Learning (pp. 723-728). Boston, MA: Springer. doi: 10.1007/978-1-4419-1428-6_1866

Soprano, A. (2003). Evaluación de las funciones ejecutivas en el niño. Revista de Neurologia, 37(1), 44-50. doi: 10.33588/rn.3701.2003237

Stevens, G., Flaxman, S., Brunskill, E., Mascarenhas, M., Mathers, C. D., Finucane, M., \& The Global Burden of Disease Hearing Loss Expert Group. (2013). Global and regional hearing impairment prevalence: An analysis of 42 studies in 29 countries. European Journal of Public Health, 23(1), 146-152. doi: 10.1093/ eurpub/ckr176

Surowiecki, V. N., Sarant, J., Maruff, P., Blamey, P. J., Busby, P. A., \& Clark, G. M. (2002). Cognitive processing in children using cochlear implants: The relationship between visual memory, attention, and executive functions and developing language skills. Annals of Otology, Rhinology \& Laryngology, 111(Suppl 5), 119-126. doi: 10.1177/00034894021110s524

Svirsky, M. A., Robbins, A. M., Kirk, K. I., Pisoni, D. B., \& Miyamoto, R. T. (2000). Language development in profoundly deaf children with cochlear implants. Psychological Science, 11(2), 153-158. doi: 10.1111/1467-9280.00231

The Joint Committee of Infant Hearing. (2019). Year 2019 position statement: Principles and guidelines for early hearing detection and intervention programs. Journal of Early Hearing Detection and Intervention, 4(2), 1-44. https:// digitalcommons.usu.edu/cgi/viewcontent.cgi?article $=1104 \&$ context $=$ jehdi. doi 10.15142/fptk-b748

Ustárroz, J. T., Molina, A. G., Lario, P. L., García, A. V., \& Lago, M. R. (2012). Corteza prefrontal, funciones ejecutivas y regulación de la conducta. In J. T. Ustárroz, A. G. Molina, M. R. Lago, \& A. A. Ardila (Coord.), Neuropsicología de la corteza prefrontal y las funciones ejecutivas (pp. 87-120), ISBN 978-84-92931-13-2. Retrieved from https://dialnet.unirioja.es/servlet/articulo?codigo $=5080142$

Wang, J., \& Napier, J. (2013). Signed language working memory capacity of signed language interpreters and deaf signers. Journal of Deaf Studies and Deaf Education, 18(2), 271-286. doi: 10.1093/deafed/ens068

Watkin, P., \& Baldwin, M. (2012). The longitudinal follow up of a universal neonatal hearing screen: The implications for confirming deafness in childhood. International Journal of Audiology, 51(7), 519-528. doi: $10.3109 / 14992027.2012 .673237$

Werfel, K. L. (2017). Emergent literacy skills in preschool children with hearing loss who use spoken language: Initial findings from the Early Language and Literacy Acquisition (ELLA) study. Language, Speech, and Hearing Services in Schools, 48(4), 249-259. doi: 10.1044/2017_LSHSS-17-0023

World Health Organization. (2020). Grades of hearing impairment. WHO; World Health Organization. Retrieved from http://www.who.int/deafness/hearing impairment grades/en/Accessed 18 May 2020

Xuan, B., Li, P., Zhang, A., \& Yang, L. (2018). Decision-making in adolescents with profound hearing loss. Journal of Deaf Studies and Deaf Education, 23(3), 219227. doi: 10.1093/deafed/eny001

Yoshida, H., \& Smith, L. B. (2003). Shifting ontological boundaries: How Japaneseand English-speaking children generalize names for animals and artifacts. Developmental Science, 6(1), 1-17. doi: 10.1111/1467-7687.00247_1

Yoshinaga-Itano, C., Sedey, A. L., Wiggin, M., \& Mason, C. A. (2018). Language outcomes improved through early hearing detection and earlier cochlear implantation. Otology \& Neurotology, 39(10), 1256-1263. doi: 10.1097/ MAO.0000000000001976 


\section{APPENDIX. Supplementary Data 1. Data extraction}

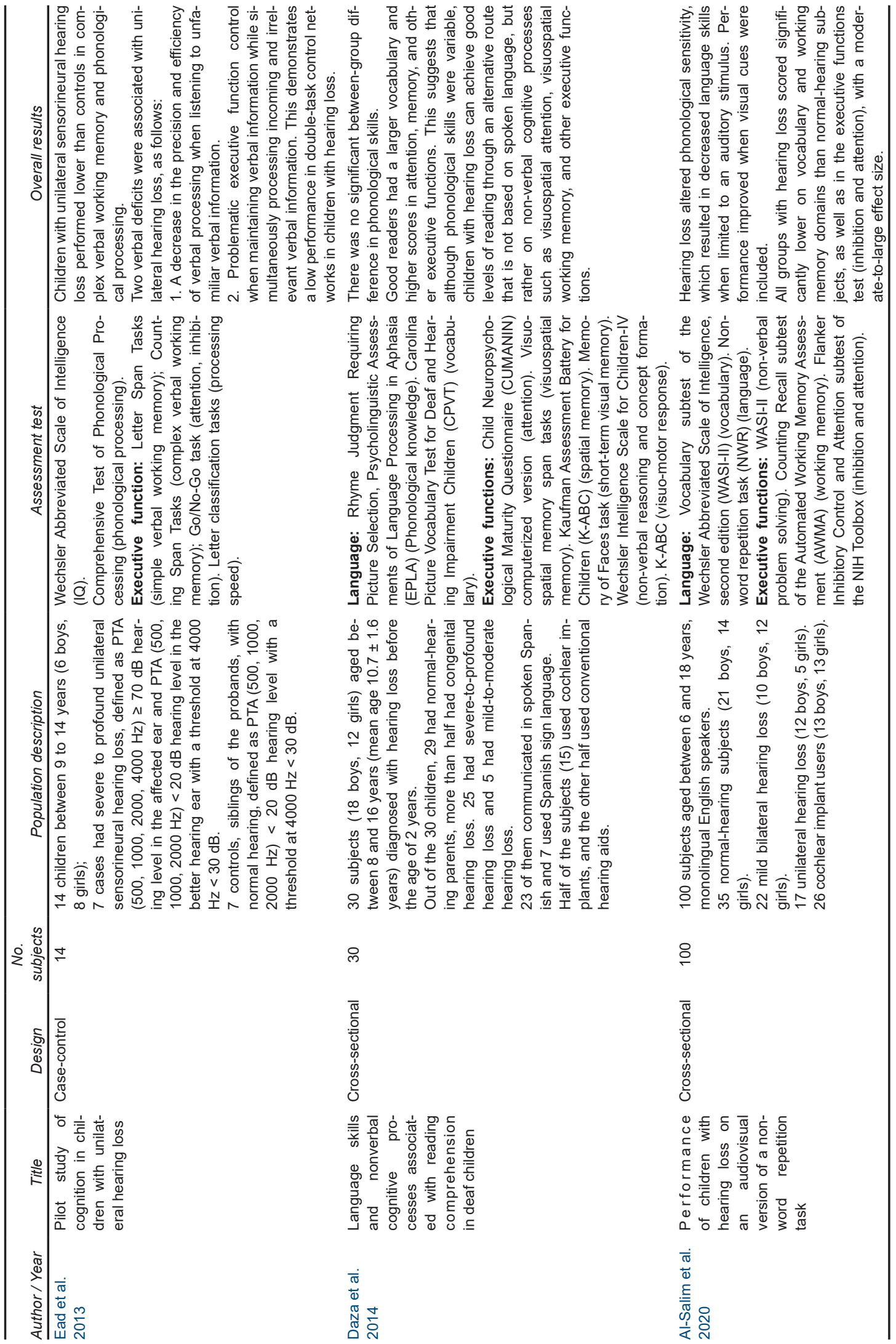














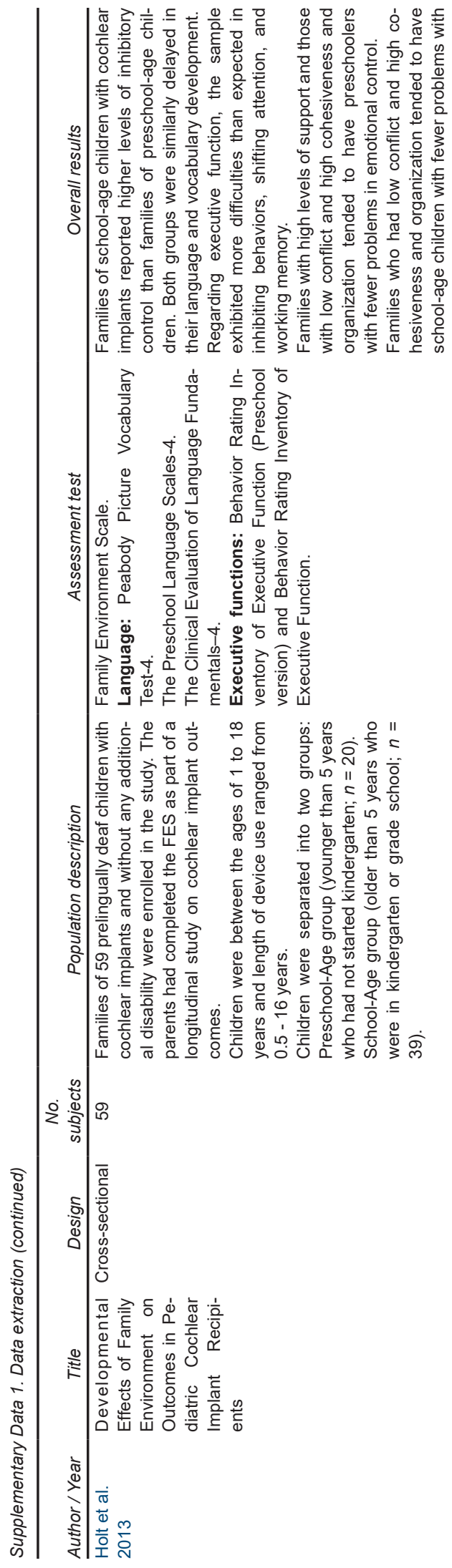

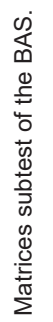

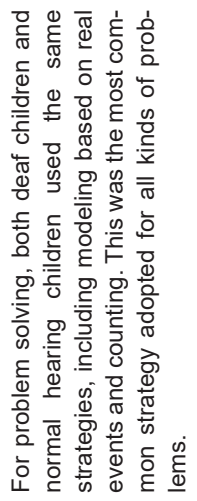

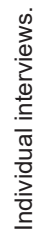

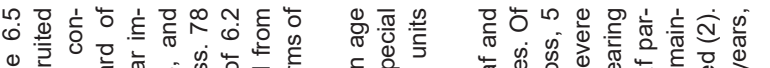



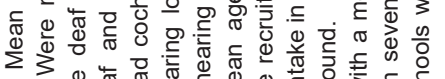

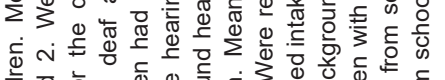

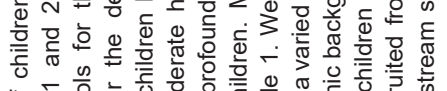

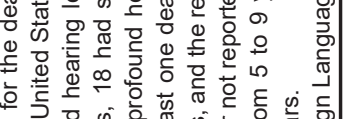

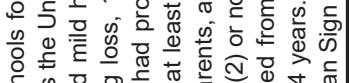

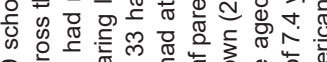

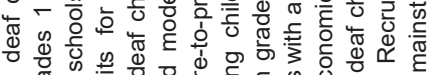

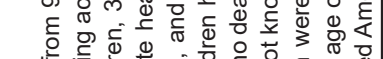

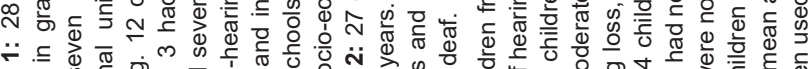

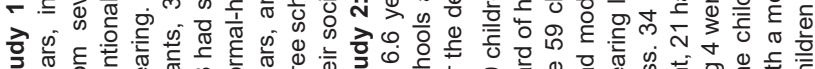

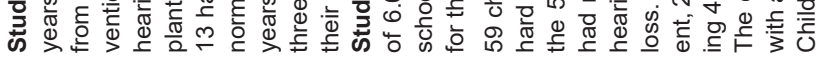

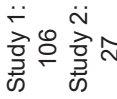

오

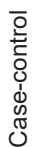

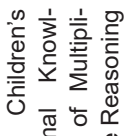

赵
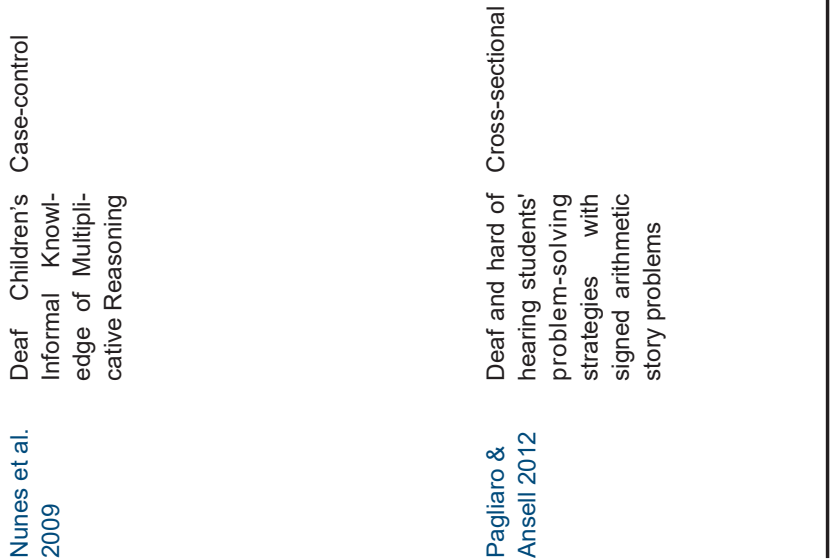


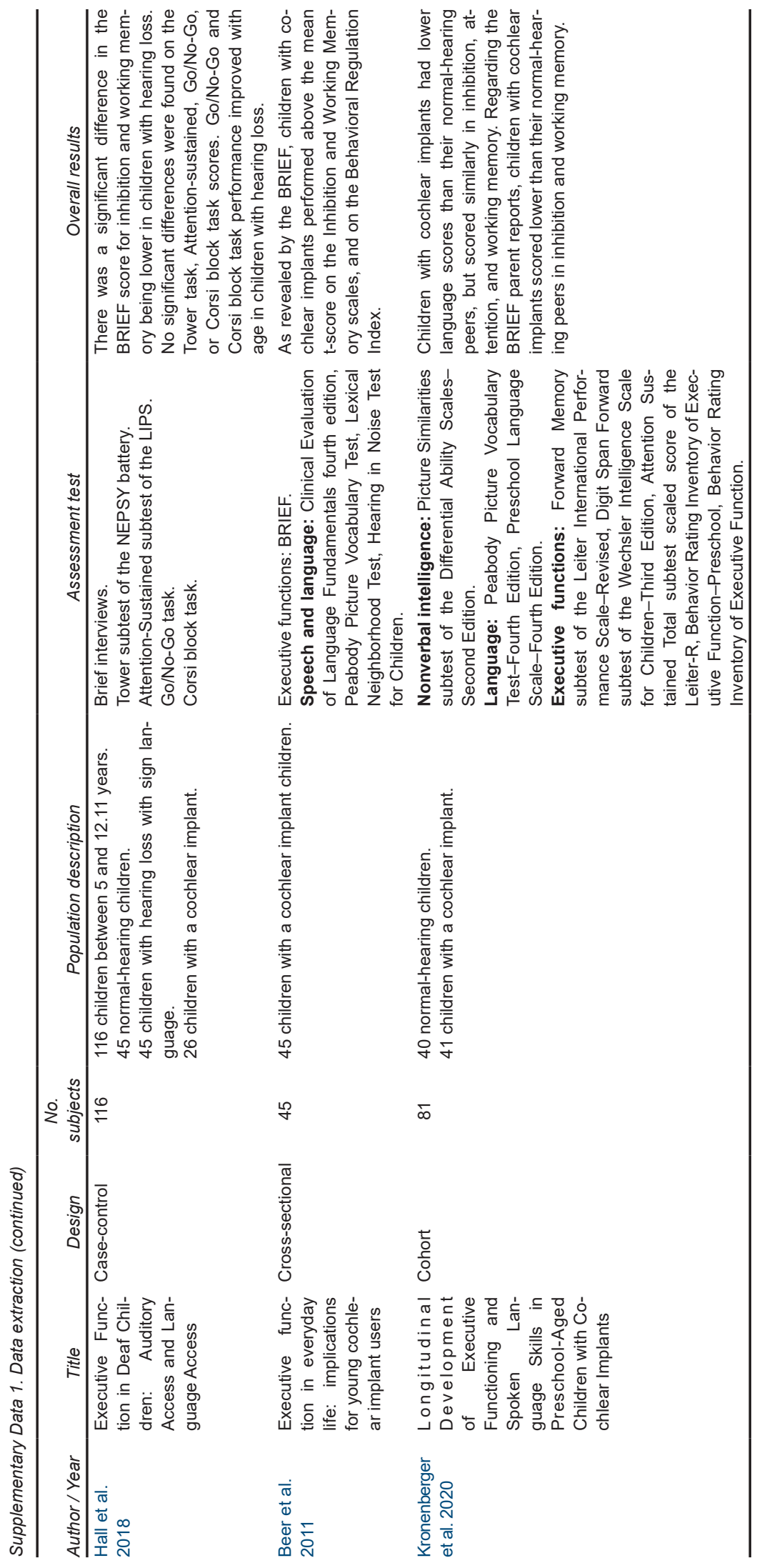

